\title{
OBSERVATIONS RELATED TO THE DESIGN AND OPERATION OF AN ARTICULATED RUDDER
}

\author{
Dumitru DASCALU ${ }^{1}$ \\ ${ }^{1}$ Associate Prof. Univ. Ph. D., " Mircea cel Batran" Naval Academy, Constanta ,Romania
}

Abstract: Work shows a complex analysis of the effects of bearing mounting a naval articulated rudder

Key words: articulated rudder, wear, bearings

\section{General description of the articulated rudder} The rudder with flaps, enroll in the current trend of optimizing the naval transport, through solutions that reduce transport costs as well to ensure its safety and increase it.

This solution is known as the articulated rudder. As we can see in Fig.1 at the base solutions of this stand a slidable oscillating mechanism where rudder blade is the element leader and articulated flap rudder blade, because of articulated slide in C, achieves an additional rotation. In this way, increases resistance hydraulic of the rudder in the gate of fluid geared by pusher-type propeller. Additional pressure difference between the front and back of the rudder makes the resulting force, acting on the hull to grow and thus maneuver veering went to be much faster. The constructive solution of these rudders is shown in detail in Fig.2. The pictures in Fig. 2, can be observed as a, from constructional, translational coupling of $\mathrm{B}$, is not protected from the seawater which thus ensures and bearing lubrication. Articulation from $\mathrm{B}$, between rudder blade and flaps, is a triple hinge made of the same materials resistant to corrosion by seawater, working lubricated by seawater.
The same solution was used for making the articulation from $\mathrm{C}$, by means of a double hinge.

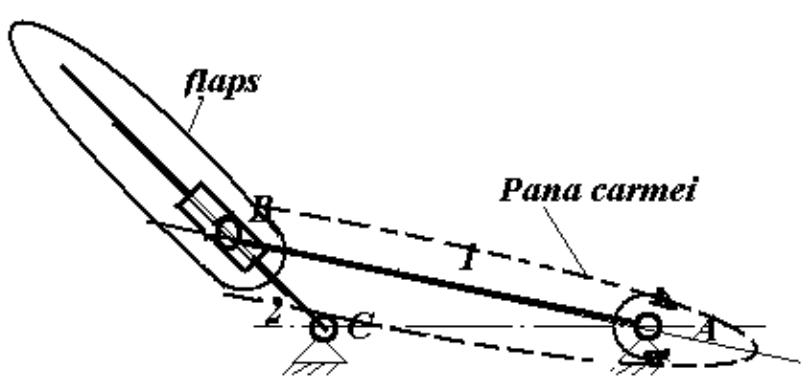

Fig.1 The basic mechanism for the rudder flaps (BEKER FLAP TYPE)

To compensate deformations of the steering mechanism under the action of water pressure the sliding mechanism is mounted with gap using the bush according to Fig. $2 \mathrm{~b}$.

This solution was imposed by the need to achieve an easier removal of the slide and the rudder as can be seen in Fig. 3. 
"Mircea cel Batran" Naval Academy Scientific Bulletin, Volume XIX - 2016 - Issue 2

The journal is indexed in: PROQUEST / DOAJ / Crossref / EBSCOhost / INDEX COPERNICUS / DRJI / OAJI I JOURNAL INDEX / I2OR / SCIENCE LIBRARY INDEX / Google Scholar / Academic Keys/ ROAD Open Access I Academic Resources / Scientific Indexing Services / SCIPIO I JIFACTOR

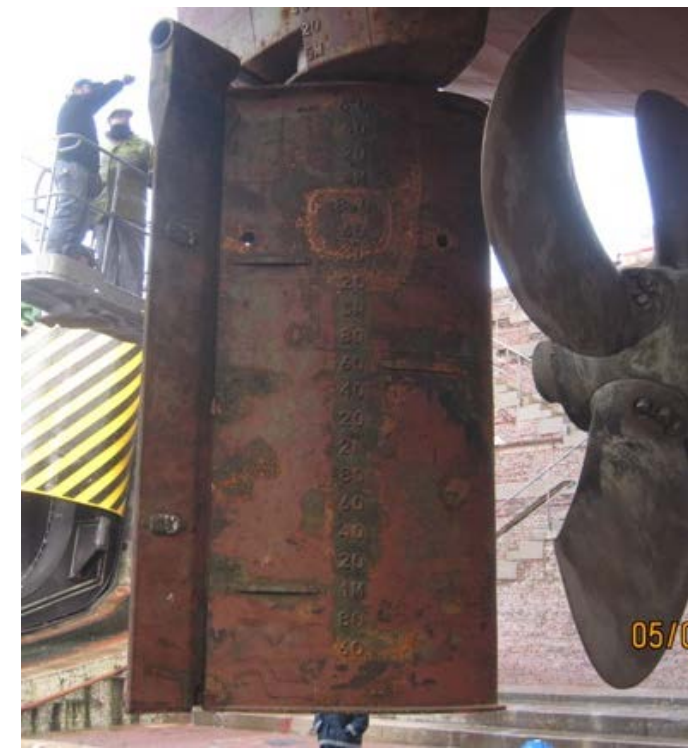

a- maximum helm rotated

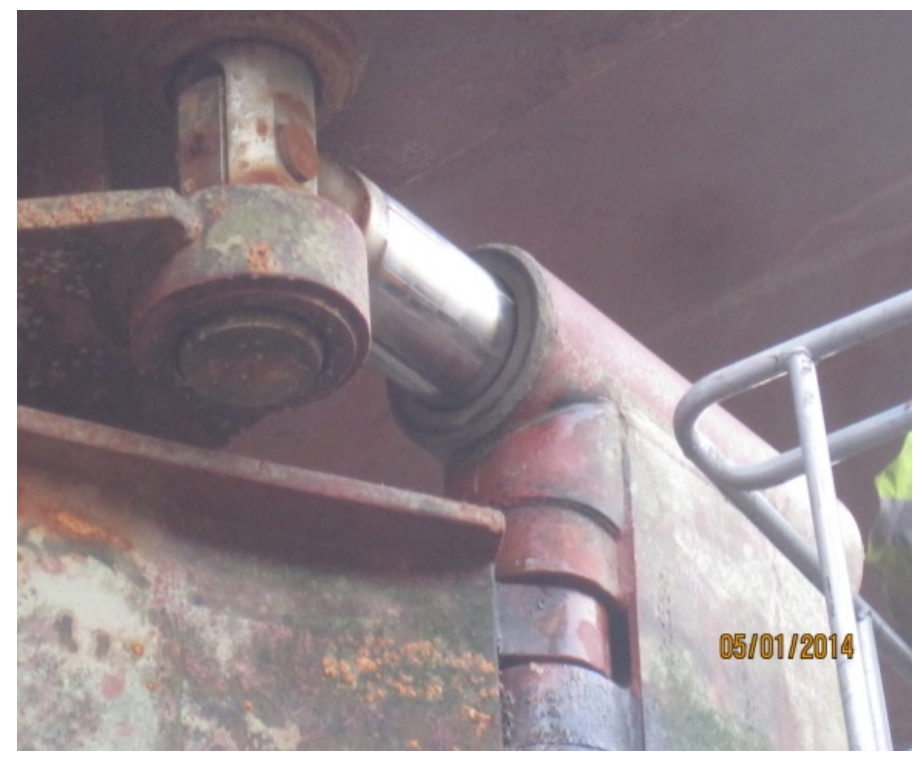

b - rudder in inclined state

Fig.2. Aspects during the inspection in order to achieve the evaluations of the rudder assembly at the docking ship.

In order to understand easily and better the phenomena that led to the need of the ascent on the dock and repairs, in Fig. 3 is rented the assembly drawing of the rudder assembly. From fig. 3.can be seen the hydraulic gear type $\mathrm{BOSCH}$. This is disposed axially within upper end of the rudder stock. The mechanism realizes the rudder with a couple of forces that is being developed by a circular piston with two rooms. Regarding of the insurance system steering shaft assembly, you can see that is a fixed three coaxial bearings. This involves precision design and assembly of achieving particularly large.

Additional force of maneuver performed by the articulated steering, obtained due to an extra hydraulic resistance given by flaps, much higher compared to simple ones. This additional strength requires additional load of the bearings system. Because the rudder is mounted in the console, lower bearing shaft has a maximum of radial load that must take. The lubrication is performed with fluid grease.

This lubricant fills the rudderstock housing volume. Column of lubricant achieves a relatively constant pressure on the lubricant film in this bearing. We can speak of a carrier film from the bearing, partially hydrodynamic and hydrostatic part. Additionally this lower bearing can be supplied with lubricant under pressure through a restrictor centrally placed in the rudder, halfway up the lower bearing. 
"Mircea cel Batran" Naval Academy Scientific Bulletin, Volume XIX - 2016 - Issue 2

The journal is indexed in: PROQUEST / DOAJ / Crossref / EBSCOhost / INDEX COPERNICUS / DRJI / OAJI I JOURNAL INDEX / I2OR / SCIENCE LIBRARY INDEX / Google Scholar / Academic Keys/ ROAD Open Access I Academic Resources / Scientific Indexing Services / SCIPIO / JIFACTOR

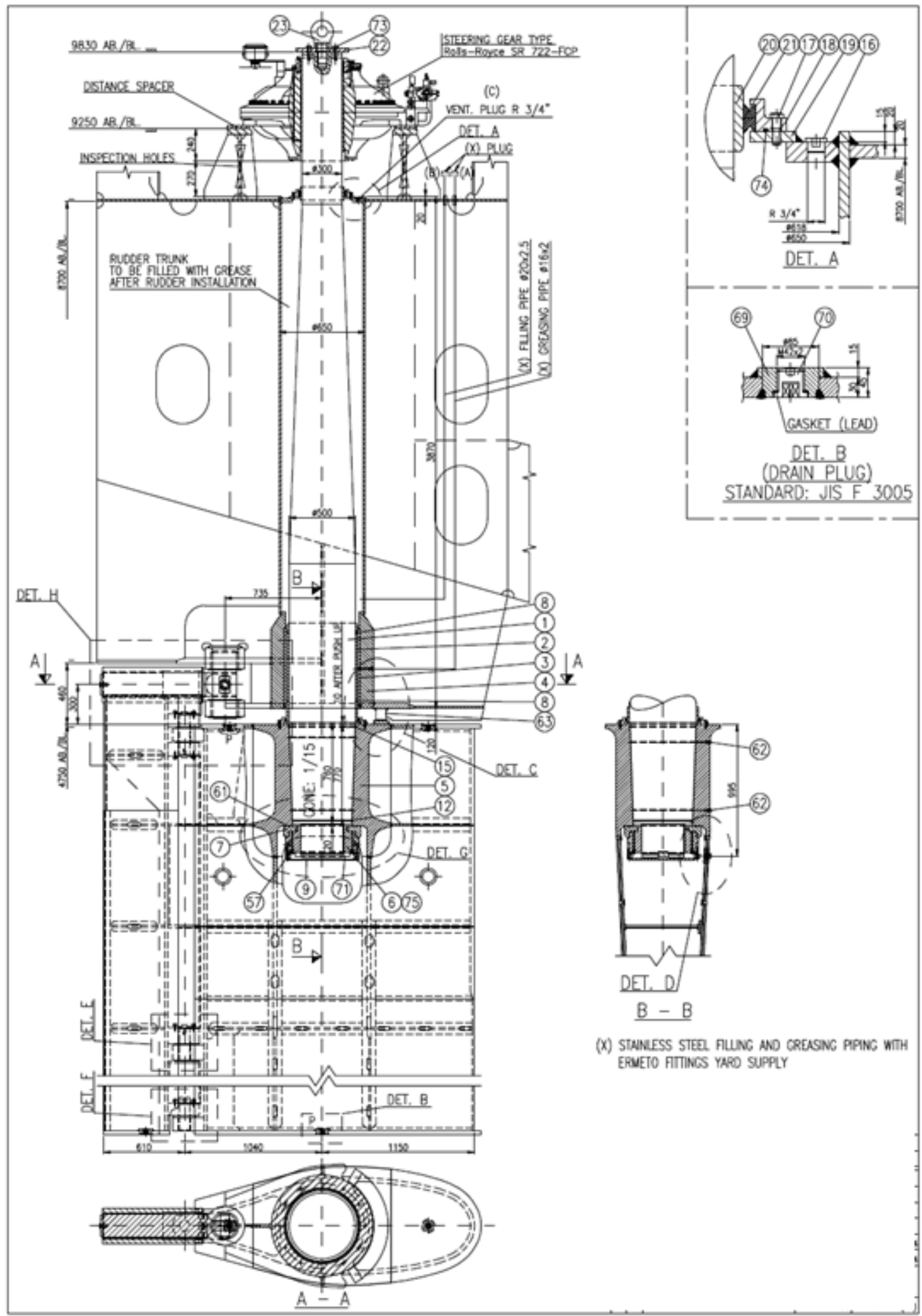

Fig.3. The Rubber Design

For the fulfillment of the mounting conditions, to the fitting rudder after repairing the bearings system, in fig. 4 is presented the fixing solution of the rudder flap by welding on each side of two pieces of sheet metal. After reassembling of the rudder the two paths will be cut and removed. Also we have noticed temporary auxiliary constructions necessary handling rudder blade. 
"Mircea cel Batran" Naval Academy Scientific Bulletin, Volume XIX - 2016 - Issue 2 The journal is indexed in: PROQUEST / DOAJ / Crossref / EBSCOhost / INDEX COPERNICUS / DRJI / OAJI I JOURNAL INDEX / I2OR / SCIENCE LIBRARY INDEX / Google Scholar / Academic Keys/ ROAD Open Access I Academic Resources / Scientific Indexing Services I SCIPIO I JIFACTOR

Also in this case, the two eyelets that were caught rigging keys to the two ends of the binding ropes after mounting on position of the rudder blade will be cut, and the welding place will be polished.

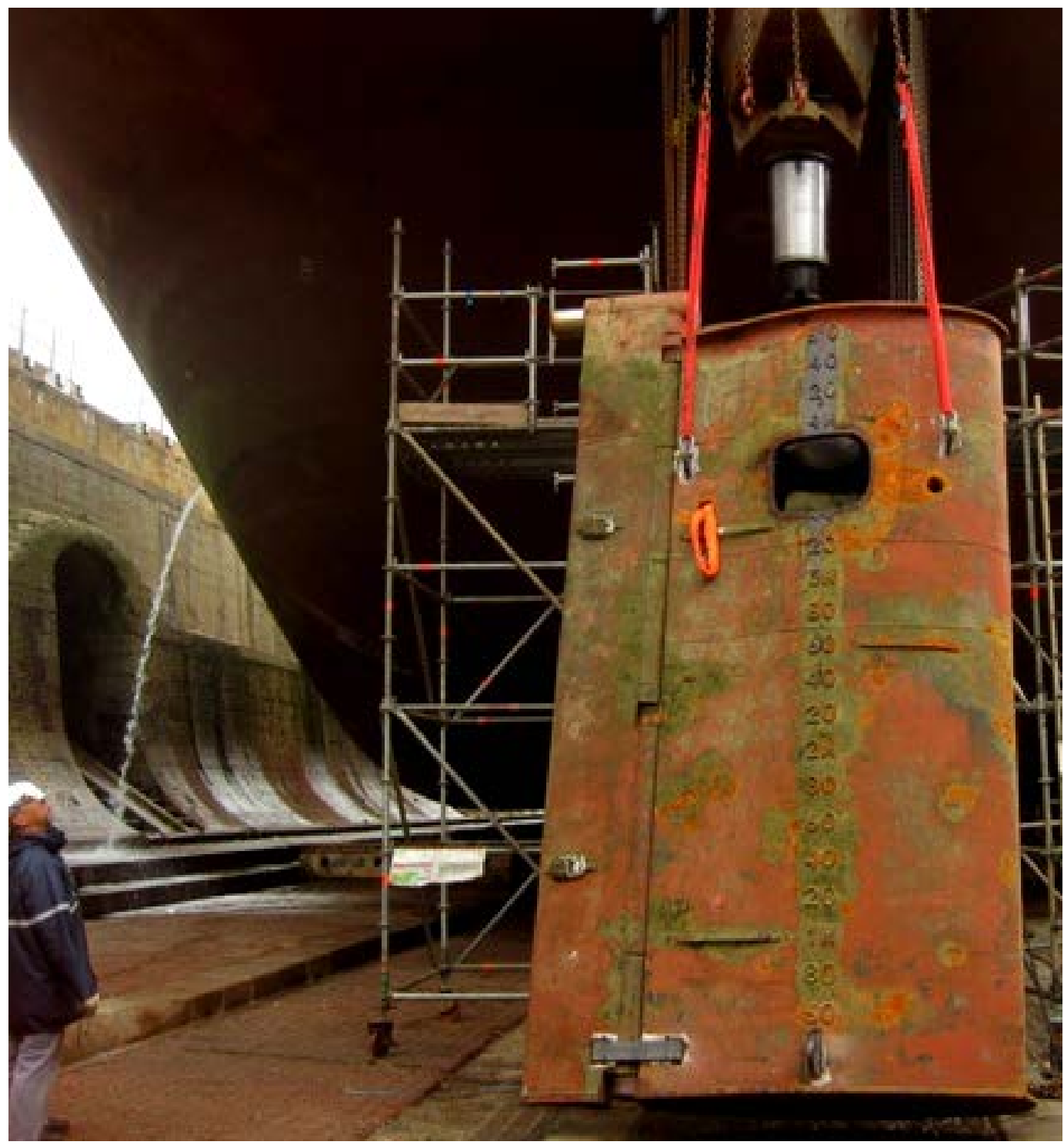

Fig.4 Example of the cone assembly and maintenance operations

\section{Aspects of constant defects}

The first reason that motivated the intervention to the steering system was the fact that in the time of the maneuvers when it was necessary the turn of the steering were generated particularly strong vibrations in the hull accompanied by particularly strong noises. These symptoms clearly showed that the bearings of the rudder assembly were worn and worked in dry regime. For this reason, along with breakage of the lubricant film appear the stick-slip phenomenons. 
"Mircea cel Batran" Naval Academy Scientific Bulletin, Volume XIX - 2016 - Issue 2

The journal is indexed in: PROQUEST / DOAJ / Crossref / EBSCOhost / INDEX COPERNICUS / DRJI / OAJI I JOURNAL INDEX / I2OR / SCIENCE LIBRARY INDEX / Google Scholar / Academic Keys/ ROAD Open Access I Academic Resources / Scientific Indexing Services / SCIPIO / JIFACTOR

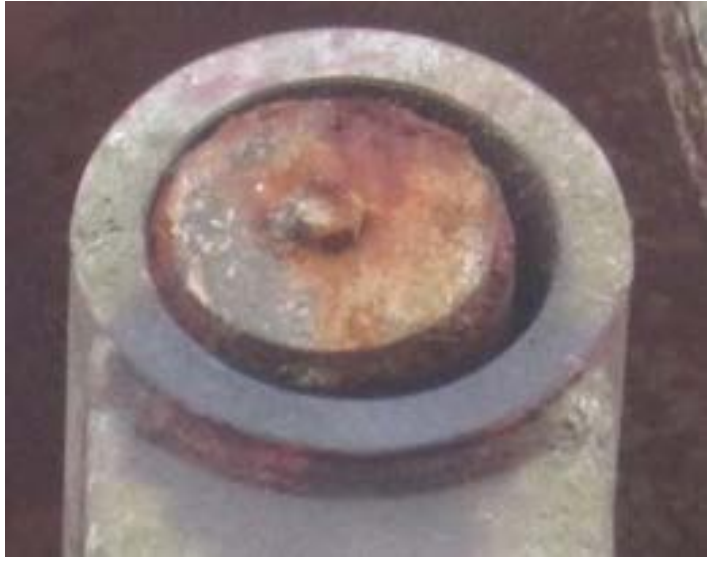

Fig .5 The wear of the circular bearing of translation between slide and bushing guilder

Another argument visible with the naked eye without disassembly is in Fig.5. The relative asymmetry between the two cylindrical surfaces of the slide and bushing guide support which should be concentric clearly prove the existence of a very large functional gap.

Obviously this gap occurred due to the wear indicates clearly exceeding the limits of wear.

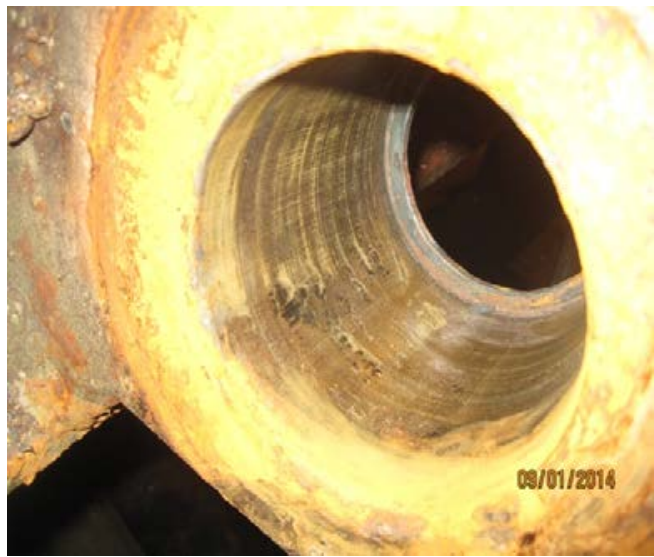

Fig.6 The bearing hole wear of antifriction alloy from fixing spur of rotated torque of the slide

From Fig.6, it is visible the depth of planar wear from the bronze support of the rotation pins of the rudder flap and that at dismantling this area of use is free of stable oxides. Establish oxides takes time to stabilize. This lack of stable oxides shows that thewearing phenomenon was continuous and highly aggressive. In the same time, there is an obvious difference between the oxidation state of this flat surface and the inner surface of the bearing. In case of one cylindrical surface, it's presents a darker surface layer, with shades indicating the presence of chemical compounds of stable reaction, with metallic luster.

One possible explanation would be given that the pressure of contact between the two surfaces and pivot bolt and the amount of the relative displacement between the surfaces with relative movement under the contract is different. It is also clear that the presence of lubricant in the presence of high pressure and relative movement with values and low speeds generates that layer with the characteristics results from the image.

The characteristics contact of the surfaces of the bearing hub can be analyzed by correlation with complementary surfaces of the torque on the shaft (fig.7). As its results from figure, is observed the transfer of oxides and other reaction products resulted after the partially lubricated contact.

We can see spots with different characteristics in terms of couplings color and gloss with slip in the contact area.

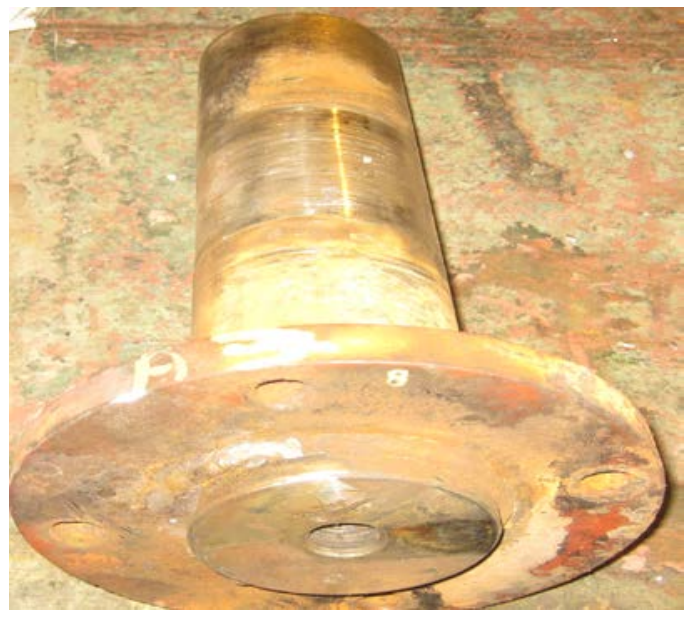

Fig. 7. Anti- wear alloy grip on bolt

A special case is consisted of some aspects of the characteristics of the fixing bearing surfaces of the main rudder shaft. As shown in fig. 3 the rudder shaft is mounted by a system of three coaxial bearings. Also we should note that theaxially fixing of the bearing is made in the driving mechanism, to avoid creating additional axial forces. Also we can't overlook the additional requests which could be induced by the deformations resulting from the stresses. In Fig.8, are shown photographs that capture the quality and level of destruction of anti-friction material surface of lower bearing of the main spindle of the rudder. Mounting the steering blade in cantilever generates a particularly high radial force.

Referring to fig. 8 we can see the effect of these requests. Although the bearing works with abundant lubrication the anti-friction surface 
"Mircea cel Batran" Naval Academy Scientific Bulletin, Volume XIX - 2016 - Issue 2

The journal is indexed in: PROQUEST / DOAJ / Crossref / EBSCOhost / INDEX COPERNICUS / DRJI / OAJI /

JOURNAL INDEX / I2OR / SCIENCE LIBRARY INDEX / Google Scholar / Academic Keys/ ROAD Open Access I

Academic Resources / Scientific Indexing Services / SCIPIO / JIFACTOR

material presents a spot light arranged on almost the entire height of the bushing bearing. The length of the radial arrangement of this mark it is greater at the bottom and less at the top. This is evidence that during the loading, the bearing shaft is bent which make that the discharge of the radial load on the bearing take variable place on its height. The complete color change of the antifriction material from bronze to white spotted shows that due to the very high pressure it was carried out it's transformations. Local high pressure caused the exfoliated of the superficial anti-friction material, followed by removal thereof with the lubricating film extrusion.

Destruction in depth of the anti-friction layer is much higher in the lower part of the bearing. This confirms the bending deformation of the main haft of the rudder in embedment.

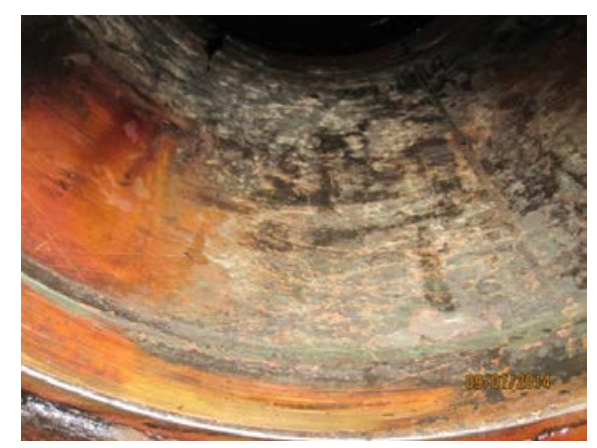

a

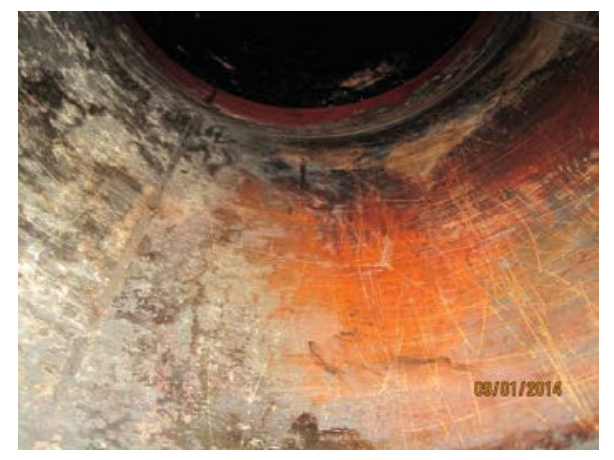

b

Fig. 8
Another interesting aspect can be seen in the way of wear, of the higher bearing for which the constructive solution is given in the detail $A$ In the rudder drawing shown in fig. 3. As it results from this drawing, to compensate for misalignment for the three bearings, and of technological errors from the design and mounting, was chosen for anti-friction material bearing deformable, made of Teflon.

The lack of an additional sealing protective system allowed entering into the working area of the bearing of impurities which were fixed on Teflon bearing,making deeper,uniform, continuous and regular wear channels (fig9). These elements shows the fact that impurities which led to the generation of these wear, were fixed on the bearing realise in time those channels. The connected, rounded shape of the profile of these wear channels, the lack of sharp edges andthe specific metallic gloss resulting from splintering shows that impurities were accumulated in time focusing on plastic material acting as an emery in the contact with theanti-friction material of the shaft.



Fig.9 Upper rudder shaft bearing wear

\section{CONCLUSIONS}

In conclusion, the new revolutionary solution requires certain improvements and refinements to achieve an increase of reliability of this subassembly with a vital role in ship operation.

\section{BIBLIOGRAPHY}

- The ship documentation

- $\quad$ Pictures taken on the disassembling of the assembly. 